\title{
Perspectives on contextual vulnerability in discourses of climate conflict
}

\author{
U. T. Okpara ${ }^{1,2}$, L. C. Stringer ${ }^{1}$, and A. J. Dougill ${ }^{1}$ \\ ${ }^{1}$ Sustainability Research Institute, School of Earth and Environment, University of Leeds, Leeds, LS2 9JT, UK \\ ${ }^{2}$ Agricultural Economics Department, Faculty of Agriculture, University of Nigeria, Nsukka, Nigeria \\ Correspondence to: U. T. Okpara (uche4purpose@yahoo.co.uk)
}

Received: 9 November 2015 - Published in Earth Syst. Dynam. Discuss.: 14 December 2015

Revised: 26 January 2016 - Accepted: 28 January 2016 - Published: 8 February 2016

\begin{abstract}
The science of climate security and conflict is replete with controversies. Yet the increasing vulnerability of politically fragile countries to the security consequences of climate change is widely acknowledged. Although climate conflict reflects a continuum of conditional forces that coalesce around the notion of vulnerability, how different portrayals of vulnerability influence the discursive formation of climate conflict relations remains an exceptional but under-researched issue. This paper combines a systematic discourse analysis with a vulnerability interpretation diagnostic tool to explore (i) how discourses of climate conflict are constructed and represented, (ii) how vulnerability is communicated across discourse lines, and (iii) the strength of contextual vulnerability against a deterministic narrative of scarcity-induced conflict, such as that pertaining to land. Systematically characterising climate conflict discourses based on the central issues constructed, assumptions about mechanistic relationships, implicit normative judgements and vulnerability portrayals, provides a useful way of understanding where discourses differ. While discourses show a wide range of opinions "for" and "against" climate conflict relations, engagement with vulnerability has been less pronounced - except for the dominant context centrism discourse concerned about human security (particularly in Africa). In exploring this discourse, we observe an increasing sense of contextual vulnerability that is oriented towards a concern for complexity rather than predictability. The article concludes by illustrating that a turn towards contextual vulnerability thinking will help advance a constructivist theory-informed climate conflict scholarship that recognises historicity, specificity, and variability as crucial elements of contextual totalities of any area affected by climate conflict.
\end{abstract}

\section{Introduction}

Several accounts of the relations between climate change and conflict are organised around three sets of ideas: "trends in climatic events", "presence of conflict triggers" and "dynamics of intervening variables". Extreme climatic events are increasing in several regions of the world (IPCC, 2014). They are envisaged as driving natural disasters and resource scarcity, and causing huge material destruction, challenging livelihoods, and spurring widespread economic downturn (Buhaug et al., 2008). Conflict triggers, such as random acts of group clashes and a history of ethnic and religious tensions, are held to combine and exacerbate the social impacts of climate change (Adger, 2010). Intervening variables (e.g. poverty, marginalisation, and inequality), which are linked to conflict triggers, are equally thought to define and shape how climate change and conflict emerge and combine (Papaioannou, 2016). These ideas have not gone unchallenged. Several studies suggesting a link between climate change and conflict have been extensively critiqued on both theoretical and empirical grounds as either being climate-centric with disproportionate focus on environmental determinism (Raleigh et al., 2014), or framed around threats posed to the sovereignty and territorial integrity of the nationstate to promote the political and military interests and development agendas of certain governments (Von Lucke et al., 2014). Yet, these ideas have remained dominant in academic and policy circles, and mainstream scholarship oriented to critiquing the ideas has been less concerned about 
proposing alternative portrayals of the climate change and conflict issue. In particular, there has been little attempt to pin down the categories of voices articulating whether climate change poses a pressing security threat, and how portrayals of vulnerability influence the discursive formation of the issue. There is a need to investigate these aspects to better advance the discussion on how to address the imbalances in climate conflict knowledge production, especially in relation to land use pathways to conflict under climatic changes.

This paper develops a new way of understanding the varying contentions amongst climate conflict discourses using discourse components typical of the broad sweep of the environmental security discourses (Adger et al., 2001; Dryzek, 2005). Specifically, it is concerned with how particular interpretations of vulnerability (see Kelly and Adger, 2000; Füssel, 2007; O'Brien et al., 2007) enable or constrain the representation of climate conflict discourses. Discourse here is conceived as a historically emergent collection of shared ideas and practices for apprehending and comprehending climate change and conflict. Crucially, discourses of climate conflict are often articulated either based on the referent object(s) whose security is threatened under climate disruptions (McDonald, 2013) or framed to tease out whether or not climate change is a factor in conflict outcomes (Scheffran et al. 2012b). In other cases, they are framed broadly around notions of "environmental conflict" and "environmental security" (Detraz, 2011). There has been no previous analysis of how framing of climate conflict links as a vulnerabilitybased question can adequately feed into the ways the links are understood.

This paper argues that different theoretical conceptualisation of the character of climate change and conflict interactions is a manifestation of a limited understanding of the degree and/or nature of overlap and distinction between the terms "threats" and "vulnerabilities". Although climate change can be a threat and also a source of vulnerability, its framing as a threat is contingent upon its capacity to drive vulnerability. Threats denote danger that is imminent or approaching, while vulnerabilities imply a demanding condition or state of weakness or powerlessness, and may not always imply a threatening one (see O'Neil, 2011, 2432). Therefore, a useful way to engage with climate conflict would be to transition from threat-centred thinking to concern about vulnerabilities (Detraz, 2011), where climate change is recognised and assessed first as an "accelerant of vulnerabilities" in linked climate conflict outcomes, before its portrayal as a "threat multiplier" (see Jasparro and Taylor, 2008 , p. 237). This way, vulnerability can be applied to understand the myriad of hidden contextual conditions (i.e. the bright spots and black holes) in climate-conflict links, and for framing responses to conflict, including climate and landbased adaptation and conflict mitigation (Scheffran et al., 2012a; Busby et al., 2014a, b).

In much of the climate conflict discourses, there is no reference to a specific interpretation of vulnerability. Since climate conflict reflects a continuum of conditional forces that coalesce around the notion of vulnerability (Ludwig et al., 2011), we posit that how vulnerability is embedded in the discourses must, therefore, be interpreted and understood through research arguments, illustrative questions, prioritised focal points and particular methodologies in bodies of texts and debates (O'Brien et al., 2007). This perspective informs the vulnerability interpretation diagnostic tool applied in this research. The research identifies discourse categories by laying out discrete expressions that depict homogeneity in messages regarding the (i) roles of climate change in conflict outcomes, (ii) perceptions regarding the referent object whose security is threatened, and (iii) how frameworks of meaning about vulnerability are portrayed (i.e. the vulnerability interpretations underpinning climate conflict discourses). This approach allows for a less subjective search for and characterisation of discourses. As such, it represents a significant departure from most previous efforts to understand the discursive construction of climate conflict and/or security in the literature. By investigating frameworks of meanings ascribed to vulnerability, using a more nuanced and less subjective vulnerability interpretation diagnostic tool, the study demonstrates how different interpretations of vulnerability may encourage or shape a particular climate conflict discourse.

The main research motivation draws largely from Gemenne et al.'s (2014) call regarding the need to re-embed the notion of vulnerability as a function of power into the discourses on climate and conflict in order to increase the prospect of explaining better the climate conflict links. This paper therefore asks the following:

- How are the different discourses of climate change and conflict constructed and represented in peer-reviewed articles?

- How is vulnerability portrayed across discourse lines and how does this influence the discursive formation of climate change and conflict issues?

- How may we frame climate conflict as a vulnerabilitybased question and what new knowledge can we anticipate with this framing (e.g. for guiding climate, land use, and conflict research)?

\section{Logic of vulnerability interpretations}

Vulnerability is commonly understood as the susceptibility of people to the harmful consequences of (climatic) shocks or stressors, yet various underlying interpretations are ascribed to it in the climate impact literature. The interpretations come under a variety of labels, e.g. "end point", "starting point" and "focal point" interpretations (Kelly and Adger, 2000), as well as "outcome" and "contextual" interpretations (O'Brien et al., 2007). In O'Brien et al.'s (2007) writing, end point and starting point interpretations convey the same meanings as 
Table 1. Interpretations of vulnerability in climate change impact studies (based on Füssel and Klein, 2006; Füssel, 2007; Kelly and Adger, 2000; O’Brien et al., 2004, 2007).

\begin{tabular}{lll}
\hline & Outcome interpretation & Contextual interpretation \\
\hline $\begin{array}{l}\text { Prioritised meaning of } \\
\text { vulnerability }\end{array}$ & $\begin{array}{l}\text { Extent to which expected net climate change } \\
\text { may harm a particular system }\end{array}$ & $\begin{array}{l}\text { Current susceptibility to climate change and variability as } \\
\text { influenced by multiple factors and processes }\end{array}$ \\
\hline Temporal reference & $\begin{array}{l}\text { Future vulnerability to climate impacts; } \\
\text { adaptation to future climate change }\end{array}$ & $\begin{array}{l}\text { Present vulnerability and adaptation to current climate } \\
\text { variability and change }\end{array}$ \\
\hline Framing & $\begin{array}{l}\text { Scientific framing of the climate change } \\
\text { problem based on physical-flows (the state of } \\
\text { nature) view }\end{array}$ & $\begin{array}{l}\text { Human security framing based on actor-system view (nature } \\
\text { and society are inseparable aspects of the same context) }\end{array}$ \\
\hline Entry point of analysis & $\begin{array}{l}\text { Projections of future emission trends and } \\
\text { scenarios of future climate hazards }\end{array}$ & $\begin{array}{l}\text { Current climatic, biophysical and contextual conditions } \\
\text { driving vulnerability }\end{array}$ \\
\hline Vulnerability approach & Integrated, risk hazard & Political economy, social or intrinsic vulnerability \\
\hline $\begin{array}{l}\text { Vulnerability and } \\
\text { adaptive capacity links }\end{array}$ & $\begin{array}{l}\text { Adaptive capacity determines vulnerability } \\
\text { Policy context }\end{array}$ & $\begin{array}{l}\text { Vulnerability determines adaptive capacity } \\
\text { technological and sectoral adaptations }\end{array}$ \\
\hline
\end{tabular}

outcome and contextual vulnerability interpretations respectively. A review of what these different terms mean shows that there are generally two main interpretations (Table 1); although there could be another interpretation that falls between the end point and starting point of a vulnerability assessment. Füssel and Klein (2006, p. 305) refer to this as "an intermediate element" of vulnerability portrayal.

Vulnerability according to the end point or outcome interpretation is focused on estimates of potential (net) climate change impacts, taking into account possible (future) adaptive responses. It represents a linear result or outcome of a sequence of analyses that involves projections of future emission trends, development of climate scenarios, biophysical impact evaluations, and identification of adaptation options (Kelly and Adger, 2000). This interpretation orients towards a static quantification of biophysical vulnerability, and relates to the level of susceptibility that is observed after adaptation has taken place (Hopkins, 2014). Vulnerability assessment based on this interpretation provides a convenient means of differentiating between net and gross climate impacts through estimates of feasible adaptations. Füssel (2007) reveals this interpretation is grounded in the integrated or risk-hazard vulnerability framework and is relevant for mitigation and compensation policies (i.e. the assistance high $\mathrm{CO}_{2}$ emitting nations offer countries who disproportionally suffer from climate impacts), and for advancing technical adaptations (e.g. irrigation schemes, supply of drought-tolerant seed varieties or structural improvements in housing).

The starting point or contextual interpretation, in contrast, presents vulnerability as a "present" lack of capacity to cope or adapt to changing climate conditions. It consid- ers vulnerability as a condition generated by multiple factors and processes, and focuses on social and ecological systems (O'Brien et al., 2007). This interpretation suggests that the starting point to understanding climate change problems in societies should be based on the locations and land use context in which climate variability and change occur. The context entails a multidimensional view of climate and society interactions, which may draw upon climatic, biophysical, and other contextual conditions (i.e. social, economic, political and institutional structures and dynamics), consistent with the political ecology framework of vulnerability, and the entitlements, local livelihoods and social capital literature (Leach et al., 1999). This interpretation is relevant for explaining how intrinsic (dynamic) vulnerability determines adaptive capacities and adaptations, and for addressing broader social development issues.

Vulnerability according to the "focal point" idea represents an overarching concept or goal that a particular vulnerability study seeks to address. It reflects the course of a particular vulnerability analysis. It is more like an indicator for identifying other interpretations of vulnerability. Relating "focal point" to the food security and natural hazards literature, Kelly and Adger (2000) make reference to the space of vulnerability in terms of exposure, risk, and capacity to cope with stress, including the consequences of stress and the associated risks of slow recovery. The focal point indicates whether a study is concerned about current, future or dynamic vulnerability of climate impacts (Füssel, 2007); sectoral sensitivities, political economy or multiple stressors (O'Brien et al., 2007); or concerned about "intermediate elements" that lie between outcome and contextual interpretations (Füssel and Klein, 2006). Because of its indicative 
nature, the "focal point" notion is often not considered as a type of vulnerability interpretation.

Outcome and contextual interpretations of vulnerability differ in their descriptions of vulnerability, temporal reference and framing, starting point of analysis, vulnerability approach, adaptation-vulnerability links and policy contexts (Table 1). Although none of the interpretations is considered more or less appropriate than another in the context of climate impacts research (Kelly and Adger, 2000), contextual vulnerability can be more apt for studying current vulnerability to the social impacts of climate change, such as conflict and violence. Differences in interpretations are often emphasised to guide climate impact assessment studies and to demonstrate the need for studies to be explicit and transparent in the interpretation of vulnerability.

\section{Analytical approach}

The term "discourse" is subject to a diverse array of definitions. Broadly, it is understood as a shared way of apprehending or constructing reality (Dryzek, 2005) or as Hajer $(1995,44-45)$ puts it - "a specific ensemble of ideas, concepts and categorisations that are produced, reproduced and transformed in a particular set of practices and through which meaning is given to physical and social realities". It contains "a corpus of expressions in which we can find homogeneity in messages as well as in expressive means" (Adger et al., 2001, p. 685). Discourses structure issues in distinct ways, define what is acceptable as "true" by society, and invoke significant power effects within a particular framework of practices (Detraz, 2011; McDonald, 2013; Ide and Fröhlich, 2015). Because they influence perceptions and interpretations of a phenomenon (and an action) by emphasising the autonomy of the acting individual and/or institution (Müller, 2008), they can be dynamic or static, dominant (when their core statements are widely accepted as true by a large majority of society) or relegated, and can be communicated in various concrete forms (e.g. through written or oral statements) (Doulton and Brown, 2009). These different perceptions offer a robust support for viewing "climate-conflict discourses" as shared assumptions and contentions about climate change and conflict links, which apparently often coalesce into a range of singular norms with common themes.

A discourse approach explores commonalities across multiple discourses competing to shape the way people, communities and authorities engage with a particular issue, including the dynamics of that competition. It provides insight into the interplay of messages, narrative and/or argumentative structures and policy perceptions (Rafey and Sovacool, 2011). Several approaches to discourse analysis in the environmental realm follow the works of Michel Foucault $(1979,1991)$. His exploration of social phenomena is often presented as classic in approaches to discourse analysis (usually in the frame of "regimes of practices" and power and/or knowledge nexus), pointing to the need to construct critical narratives of distinct stories of 'realities' that constitute a discourse (Hewitt, 2009). Inspired by Foucault's idea, Hajer (1995) provides insights concerning this aspect, particularly in relation to what should constitute the objects and/or elements of a discourse analysis, e.g. metaphor, storyline, and discourse coalitions. He suggests that everything we perceive as discourses, which influence how societies engage with an issue (e.g. climate change), should be analysed in the context in which they are discursively constructed. McDonald (2013) for example, has focused on the use of textual and speech storylines and/or dimensions based on insights from Hajer's (1995) writings in his critical synthesis and/or analysis of discourses of climate security. Ideas from these previous studies inform our analytical approach for climate conflict discourses. Specifically, we focus on units of textual communications for climate conflict storylines using distinct categories of discourse components (i.e. sets of key discourse elements - Table 2) drawn from a synthesis of the fundamental discourse components outlined by Adger et al. (2001), Dryzek (2005) and McDonald (2013) for the analysis of the broad sweep of environmental security discourses. Similar to Doulton and Brown (2009), we find the discourse components (Table 2) framework particularly useful for a more explicit portrayal of the basic storylines across different climate conflict discourses, and also because they give a less subjective basis from which to assess discourse lines. Although this study does not emphasise the range of actors articulating a particular discourse or the political agenda they pursue, it nonetheless recognises dominant discourses and the vulnerability thinking that they encourage.

To investigate the framework of meanings ascribed to vulnerability, in particular how interpretations of vulnerability enable or constrain the ways in which climate conflict relation is understood, we develop a vulnerability interpretation diagnostic tool (VIDT), based on Füssel (2007) and O'Brien et al. (2007). The tool (Table 3) uses illustrative research questions, focal points, methods, and policy suggestions that appear in the body of texts as clues to deduce the particular vulnerability interpretations implied. The study demonstrates that the tool can be usefully employed for more specific issues such as climate and conflict, and in the identification of the variables that feed into any sequence of climate conflict analysis.

This research uses peer-reviewed sources as the focus of analysis - because they are based on original research, convey credibility and provide reliable insights (including their relative ease of analysis) (Atkinson et al., 2015). Searches for articles were based on a close examination of articles that suitably meet the criteria specified in Table 4. We used the search terms "climate change and conflict" OR "climate conflict" OR "climate violence" OR "climate security" AND "vulnerability" to screen the Web of Science (WoS) and Scopus databases based on Title, Abstract and Keywords, and "climate, violence, security, conflict, vulnerability" on the 
Table 2. Analytical approach for discourse analysis of climate conflict peer-reviewed articles.

\begin{tabular}{|c|c|}
\hline Surface and/or external descriptors & These recognise the title, abstract, and keywords of the article \\
\hline $\begin{array}{l}\text { Central entities and/or issues recognised } \\
\text { or constructed }\end{array}$ & $\begin{array}{l}\text { This specifies the ontology of the issue; how climate-conflict phenomena are } \\
\text { understood; the role of climate in conflict; the referent object being } \\
\text { threatened; definition of the nature of the threat; and the scientific evidence } \\
\text { expressed based on context }\end{array}$ \\
\hline $\begin{array}{l}\text { Assumptions about causality and } \\
\text { mechanistic relationships }\end{array}$ & $\begin{array}{l}\text { The likely linkages and impacts of climate change on conflicts across } \\
\text { different scales; the degree of uncertainty }\end{array}$ \\
\hline Normative judgements & $\begin{array}{l}\text { Perceptions of responses for dealing with climate threats, policy prescriptions } \\
\text { on social impacts; extent to which the issue should be a priority }\end{array}$ \\
\hline Vulnerability portrayal & Framing of meanings ascribed to vulnerability in discourses \\
\hline
\end{tabular}

Table 3. Diagnostic tool for identifying different interpretations of vulnerability in climate conflict research (partly based on Füssel, 2007 and O'Brien et al., 2007).

\begin{tabular}{lll}
\hline & Outcome vulnerability & Contextual vulnerability \\
\hline Illustrative research questions & $\begin{array}{l}\text { Are human activities contributing to global warming and } \\
\text { insecurity? What are the expected net impacts of climate } \\
\text { change and conflict in different regions? }\end{array}$ & $\begin{array}{l}\text { Is climate change a relevant security } \\
\text { problem? Why are some groups more affected } \\
\text { by climate-induced conflict than others? }\end{array}$ \\
\hline $\begin{array}{l}\text { Focal points/starting point of } \\
\text { analysis }\end{array}$ & $\begin{array}{l}\text { Future implications of climate change on security and } \\
\text { conflict; scenarios of potential climate change and conflict } \\
\text { interactions, dynamic cross-scale integrated assessments }\end{array}$ & $\begin{array}{l}\text { Past and current climate variability and } \\
\text { change interactions with conflict; livelihoods, } \\
\text { political economy, place-based and internal } \\
\text { contextual issues (multiple factors and } \\
\text { processes) }\end{array}$ \\
& $\begin{array}{l}\text { Simulations/scenario based approaches; integrated } \\
\text { assessment models }\end{array}$ & $\begin{array}{l}\text { Longitudinal, cross-sectional surveys, } \\
\text { household surveys, quantitative/qualitative } \\
\text { case studies, context-specific indicator } \\
\text { approaches }\end{array}$ \\
\hline Methods & $\begin{array}{l}\text { Address local constraints in vulnerable areas } \\
\text { through direct aids, conflict preventive } \\
\text { actions, building socio-economic adaptation } \\
\text { capacities, promoting internal conflict } \\
\text { resolution, supporting livelihood security etc. }\end{array}$ \\
\hline Policy recommendations & $\begin{array}{l}\text { Reduce GHG emissions, technical and sectoral adaptations, } \\
\text { prevent trading in arms, securitisation/militarisation of } \\
\text { climate change etc. }\end{array}$ &
\end{tabular}

Google Scholar (GS) search engine. The search process covered the period 2007 to 2015 (last access: 11 August 2015). This time frame covers a period when issues about climate security and conflict became markedly pronounced as a subject of growing international public concern, especially following the publication of two Intergovernmental Panel on Climate Change reports (IPCC, 2007, 2014). Similarly, this period allows for an in-depth engagement with advances in climate conflict issues, particularly in terms of whether and how vulnerability had become an integral part of the discourses/analyses. The search process resulted in a database of 34 articles that articulate climate conflict links and that made reference to vulnerability following the criteria outlined in Table 4.
We utilise Tables 2 and 3 to analyse each selected article to more precisely detect the range of discourses depicting homogeneity in stances. Our approach evidently demarcates what represents a particular way of viewing climate-conflict ideas. The identified stances and discourses are presented in Sect. 4. Each discourse is described by using illustrative quotes, basic storylines, and a brief outline of the discourse components and/or contents.

\section{Characterising discourses of climate conflict}

Nine general stances regarding interactions between climate change and conflict were identified from the taxonomy of discourses present in the peer-reviewed sources. The stances 
Table 4. Article selection criteria.

The scholarly interest of the article is on the interactions between climate change and conflict or security

The article is focused on climate causes only or a combination of location-specific climatic and contextual issues, or the article questions and denies the rationale for a climate connection in conflict outcomes (articles showing mixed, unclear ideas were excluded)

The article is peer-reviewed and published between 2007 and 2015

Articles in which the keyword "vulnerability" is mentioned, either explicitly or implicitly, at least once in the title, abstract, keywords or in the entire text, excluding the reference list (Desktop Mendeley Reference Manager enabled the screening of texts depicting vulnerability/vulnerabilities)

The article is widely available in English and accessible through electronic media (either by an open access or subscription only platform or both) to readers from various backgrounds

Table 5. Typology of climate conflict discourses and associated stances across the peer-reviewed sources.

\begin{tabular}{|c|c|}
\hline Discourse lines & Stances* \\
\hline For "climate conflict" & Climate change is a "threat multiplier", an "accelerant of instability". \\
\hline Climatic determinism & $\begin{array}{l}\text { Climatic conditions and events directly influence the propensity for violent conflict (Burke et al., } \\
\text { 2009; Hsiang et al., 2011). }\end{array}$ \\
\hline Context centrism & $\begin{array}{l}\text { Indirect linkages demonstrate that the "state of nature" and "nature of the state" are inseparable } \\
\text { aspects of the same context across different scales (Raleigh et al., 2014). }\end{array}$ \\
\hline - National security threat & $\begin{array}{l}\text { Threats from the manifestations of climate change will challenge the sovereignty, territorial } \\
\text { integrity and institutional capacity of the nation-state, undermining the national "way of life" } \\
\text { (Busby, 2008; Morales Jr., 2015). }\end{array}$ \\
\hline - Human security threat & $\begin{array}{l}\text { The poor are powerless victims; climate change will drive human insecurity and violent } \\
\text { confrontations by shrinking the resource base anchoring livelihoods and by undermining political } \\
\text { and economic stability (Zografos et al., 2014). }\end{array}$ \\
\hline - International security threat & Climate change is likely to cause planetary upheavals (Brown and McLeman, 2009). \\
\hline - Ecological security threat & $\begin{array}{l}\text { Climate change will accelerate (negative) systematic structural change in people-biosphere } \\
\text { relationship, and undermine moral obligation humans have to preserve plants, animal species and } \\
\text { other living beings (McDonald, 2013). }\end{array}$ \\
\hline Against "climate conflict" & $\begin{array}{l}\text { Branding conflict as an outcome of climate change is misleading and fails to address the } \\
\text { ideological variables driving conflict. }\end{array}$ \\
\hline Denial claims/detached & Conflict is a social issue/construct, its drivers have no link with climate change (Selby, 2014). \\
\hline
\end{tabular}

differ in their arguments "for" and "against" considerations of climate change as a security issue (or as a threat multiplier). The stances arguing for climate conflict (seven stances in all) affirms a security threat position across different scales. One specific stance with a climate-centric viewpoint suggests that climatic conditions and events directly and dominantly influence conflict and violence. Another stance based on a context-centric narrative affirms indirect linkages through a confluence of factors which evidently differ across different scales (national, human, global, and ecological), particularly in terms of what may constitute "the state of nature" and the "nature of the state" across varying contexts. Next comes the opposing stances (two stances in all) - which hold that conflict under climatic trends is a social construct, and that climatic changes need not be characterised as a security issue. The stances and the discourses linked to them are outlined in Table 5. All shades of conflict and violence types, including climatic stressors, events, and extremes are considered in categorising the discourses. We focused predominantly on the textual dimensions and practices of communicating and reinforcing discourses. Our categorisation does not include a neutral stance, i.e. messages that are somewhat ambivalent about the climate conflict issue.

\subsection{Discourse 1: climatic determinism}

Large deviations from normal precipitation and mild temperatures systematically increase the risk of many types of conflict, often substantially (Hsiang et al., 2013, p. 1).

Temperature variables are strongly related to conflict incidence ... with a $1^{\circ} \mathrm{C}$ increase in tem- 
perature ... leading to a $4.5 \%$ increase in civil war... (Burke et al., 2009, p. 20670 ).

Climatic determinism demonstrates that warming climates influence irritability, aggression, and violent intergroup conflicts. Central to this discourse is a thermal stress hypothesis grounded in research mainly from psychology of social conflict and aggression (Anderson and DeLisi, 2011). In particular, extant studies that use quantitative methods to link conflict to climate in global or regional data sets affirm that heat and aggression are closely linked by illustrating that physically uncomfortably hot conditions (e.g. during El Niño events) can increase the likelihood of physical aggression and violent conducts (Hsiang et al., 2011). This discourse prescribes an almost instant "conflict" response to thermal extremes and represents a world view in which climate change is conceived as a dominant factor in, and a key entry point to the climate conflict storyline. By promoting a direct effect of uncomfortably warm temperatures on conflict and violence, and therefore placing climate trends as the central focus, the discourse evidently suggests a modern form of "biophysical or environmental determinism" (Raleigh et al., 2014). Indeed, the discourse draws upon enlightenment ideals of positivist science to suggest that more knowledge about the dynamic climate/biophysical/land use systems will enable humankind to better mitigate climate impacts, and cope with social conditions such as conflict escalations.

\subsection{Discourse 2: context centrism}

Political and economic, rather than climatic factors, can be a key source of human insecurity (Zografos et al., 2014, p. 335).

The context centrism discourse in which the notions of human, national, global, and ecological security are apart, is often cast from a deterministic storyline that encourages viewing climate change as a threat to the extent that it precipitates threats across diverse scales (Detraz, 2011; McDonald, 2013). In the frame of political ecology and neoMalthusian perspectives, it embeds the subjects whose security is threatened, including specific causal mechanisms, as a central premise to offer support for connections between climate change and conflict. Specifically, it is concerned about tracing multi-level linkages, including decisionmaking, governance, and hierarchies of power (Kallis and Zografos, 2014). Statements pointing to climate change as fuelling more droughts and famine, more forced migration and/or mass displacement, hikes in food prices, scarcities of resources anchoring human livelihoods, land use changes, and negative changes in economic growth are often invoked to explain how climate change drives conflicts and violence (Gemenne et al., 2014; IPCC, 2014). Generally, studies articulating a context-centric view emphasise that (i) climateconflict links are multi-directional, i.e. there is not a simple one-way connection, (ii) several themes and variables are involved, pointing to climate change as one of a range of factors in conflict outcomes, (iii) sub-Saharan Africa and southern and/or central Asia present potential locations where evidence is most stark, and (iv) climate change is associated with low level conflicts. The discourse concentrates on what must be done to address some known drivers of conflict under climatic changes to create resilient societies (Dumaine and Mintzer, 2015).

\subsection{Discourse 3: denial claims}

Climate change ... need not be characterised as fundamentally a security issue (Gartzke, 2012, p. 177).

Quantifications of climate conflict links are of dubious value, since they inevitably rest upon coding and modelling premises that are arbitrary and sometimes even untenable (Selby, 2014, p. 20).

... scholars who study conflict itself are less persuaded by the importance of climate as a factor in outbreak of conflict ... (King and Mutter, 2014, p. 1248).

Denial claims discourse does not deny climate change, nor imply that its influence will not be problematic. Rather, it questions the existence or severity of climate change impacts on conflict outcomes, insisting that claims about climate conflict are insufficiently supported by scientific evidence (Slow, 2013). Most studies here either establish "no link" (Gartzke, 2012; Koubi et al., 2012), demonstrate "little evidence" (Wischnath and Buhaug, 2014) or view climate conflict predictions with scepticism (see Mason and Zeitoun, 2013). This discourse draws mostly upon a philosophical and/or traditional security type of thinking that presents conflict as a social construct, a somewhat "militarised framing" or "heterodox idea" that is critical to claims about relations between environment/climate and conflict (Deudney, 1990). By constructing realities based on a combination of historical antecedence and current economic, political and cultural contexts, the discourse argues for a need to explore conflict in more complex ways than simply pointing to climate change, and suggests tackling more pressing challenges such as terrorism, HIV and poverty that plague Third World countries (Selby, 2014; Floyd, 2015).

Table 6 gives a summary of the different discourses, showing key similarities and differences, and how they are constructed using the central entities and/or issues recognised, the assumptions about causality and mechanistic relationships, normative judgements inferred and vulnerability portrayals. Although the constructed discourses differ considerably in their conceptualisation of the roles of climate change in conflict events, we observed, as have others (e.g. Ide and Scheffran, 2014; O’Loughlin et al., 2014; Buhaug, 2015), 

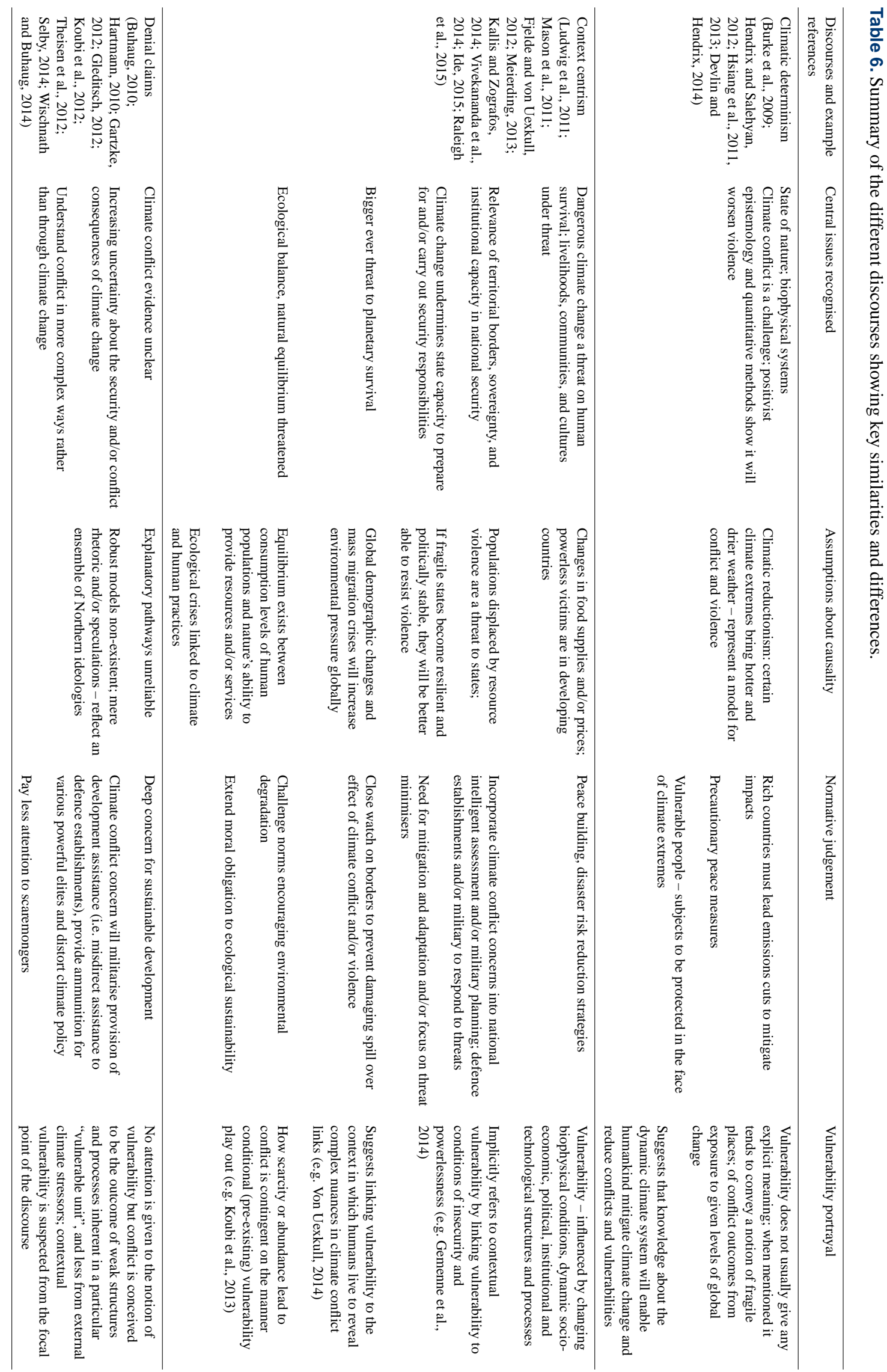
that studies within particular discourses - in particular the quantitative climate-centric and context-centric studies also differ in the conclusions and policy suggestions they provide. This is explained by the (i) varied climate and conflict data sets used, (ii) different quantitative and qualitative definitions and scope of conflict employed, (iii) different climate change parameters, (iv) benchmark model specifications (i.e. modelling problems), including varied evaluation and statistical procedures, and (v) choice of spatial scales and theories.

\section{Portrayals of vulnerability across climate conflict discourse lines}

... much of the emerging climate security discourse contains elements of early environmental security research which many critics have found to be problematic (Jasparro and Taylor, 2008, p. 237).

"Vulnerability" is mentioned much less frequently in peerreviewed evidence for and against climate conflict. However, there are differences across discourse lines. For example, the somewhat "direct link" premise upon which the climatic determinism discourse is based ordinarily seems to deemphasise vulnerability, indirectly implying that previously recorded incidences of climate conflict may not have happened because an entity between changes in climate and onset of conflict is vulnerable. Nonetheless, based on the VIDT approach, we note that references to the state of nature and a biophysical frame shift the discourse towards a vulnerability description that suggests an outcome interpretation. This position is particularly evident in assessments where the probability of conflicts arising is linked to a single net climatic event (e.g. Hsiang et al., 2011). As vulnerability is generally given less explicit consideration, it is highly likely that the discursive formation of climatic determinism has progressed without attention to conditional elements shaping vulnerability.

This position is in sharp contrast to a context centrism discourse where discussions about vulnerability often invoke the contexts in which humans live or the boundaries in which states operate (Barnett and Adger, 2007). In high-risk regions of Africa where climate change impacts are far-reaching and where contextual conditions imply weakness, vulnerability is interpreted in the language of insecurity and presented as a condition of powerlessness (Gemenne et al., 2014). This discourse emphasises that climate change not only causes conflict through resource scarcities or a decline in national incomes, but by increasing human and national vulnerabilities. Indeed, climate change produces its effects more within extremely vulnerable systems (Sherbinin, 2014).

Broadly, vulnerability is conceived as occurring and increasing conflict outcomes of climate change when and where individuals, communities and states lack the capacities necessary to end internal and external vulnerability drivers (Busby et al., 2014a; Kallis and Zografos, 2014). Adger's (2010) writing is a good example of how vulnerability is portrayed here, particularly through a human security framing. It is the consideration of human security - in terms of conditions that make people susceptible to harms under climate change (e.g. ecological marginalisation, deprivation, disempowerment) - that makes the inclusion of vulnerability in contextual climate conflict studies richer and more meaningful. As climate change is more relevant for human security and low-level conflicts than for other security types (Floyd, 2008, 2015), reference to contextual vulnerability is most visible in studies that follow a human security frame.

Context centric discourse shows that interpreting vulnerability in the notion of contextual dynamics can reveal the complex nuances of vulnerability, and also of climate conflict interactions. One facet of this complexity presents vulnerability as a potential transformative process (O'Brien et al., 2007), implying that it could be beneficial if it leads to the creation of positive strategies for better governance, resilience, adaptability or peace building, particularly in conflict-prone communities facing climate extremes. On the other hand, it can be negative if it reverses moves towards peace and cooperation by increasing conflicts and social instability. The positive transformative aspect of vulnerability is particularly silent in this discourse because vulnerability is widely viewed as "bad news", as providing space for climate change to thrive and inflict harms on humankind (Adger, 2010). Because the discourse of context centrism emphasises that climate conflict cannot be separated from contextual factors driving vulnerability (which are often unique to every society), it is possible that portrayals of vulnerability as a contextual issue may have played a role in shaping the various stances associated with this discourse.

Denial claims is the most robust of the discourses in terms of vulnerability considerations. Similar to the context centrism discourse, this discourse conceives conflict as an element of social vulnerability, emanating from structures and processes inherent in a particular "vulnerable unit" and less from "external climatic forces". It recognises internal contextual variables that often shape outcomes of, and responses to, conflicts under climate change, and thus gives room to suspect a contextual vulnerability interpretation. This position is implied, albeit implicitly, in key studies such as those by Bergholt and Lujala (2012), Koubi et al. (2012), and Buhaug et al. (2014).

Although context centrism and denial claims discourses are seen as supporting a contextual vulnerability portrayal in expounding the role of climate change in conflict, whether and how vulnerability is portrayed seems likely to also depend on the country from which a particular study originates. Schafer et al. (2016) show that studies grounded in western countries strongly focus on national and global security/conflict and often give limited attention to the notion of vulnerability. In contrast, studies from developing and/or emerging economies place greater emphasis on human se- 
curity (and to key resources such as water, land, and food as important catalysts), and therefore tend to give more attention to vulnerability (Zografos et al., 2014). Similarly, as more disaggregated sub-national studies have gained traction in recent years (Raleigh and Kniveton, 2012; Papaioannou, 2016), and as "qualitative-focused studies" demonstrate a more engaging link with issues around vulnerability (especially by paying attention to the uniqueness of individual locations and their power dynamics concerning access and governance of public resources, including communal land; Adger et al., 2013), it is likely that contextual vulnerability considerations will become more central to climate conflict scholarship.

\section{Advancing the notion of contextual vulnerability}

... estimating a model without consideration of specific locations of violence across a large region over a long time period hides a myriad of contextual conditions (O'Loughlin et al., 2012, p. 18347).

... to enhance specification of theoretical arguments ... maintenance of the recent emphasis on conditional effects ... is necessary (Meierding, 2013, p. 185).

The recent rise in calls to pin down more subtle and complex indirect causal mechanisms and contexts "under which climatic events plausibly may have a measurable impact on conflict dynamics" (Buhaug et al., 2014, p. 396) reflect an increasing sense of contextual vulnerability. Arguably, vulnerability in the totality of its meaning cannot be suitably portrayed in climate conflict research without reference to context and dynamism. Such a position was already apparent in studies from Scheffran et al. (2012a), Adger et al. (2013), Busby et al. (2014b), Ide et al. (2014) and Wischnath and Buhaug (2014), which largely endorse a context centrism discourse frame. The most immediate insight here illustrates that it is preferable to say that to understand climate conflict relations is to understand nuanced and context-sensitive intervening factors. Halvard Buhaug (2015, p. 271) captures the fundamental nature of this position, suggesting that:

... there is no mechanistic link between the environment and society that dictates the same social response to a climatic phenomenon across contexts. Societies differ with respect to environmental vulnerability, coping capacity and ability to adapt, and also with respect to exogenously defined drivers of latent conflict risk.

The imperatives of contextual vulnerability increasingly challenge a deterministic narrative of scarcity-induced conflict (Selby and Hoffmann, 2014). They redefine the way we think about the subtle patterns certain climatic conditions and extremes (e.g. El Niño events) relate to conflicts in practice (Koubi et al., 2013). Expanding climate conflict research to incorporate knowledge of contextual vulnerability processes and directionality does not require great conceptual or analytical stretching (Brown and McLeman, 2009). As has been echoed in the environmental security and vulnerability literature, locational climate conflict and vulnerability share similar structural determinants: poverty, fractured social and political structures, and resource depletion (Adger et al., 2013). The breadth and scope of these are most powerfully advanced in the analytical framework proposed by Scheffran et al. (2012b), which draws upon environmental (e.g. ecosystem damage, biodiversity losses, etc.) and human (e.g. livelihood losses, asset depletions, etc.) vulnerabilities as key elements of contextual vulnerability in tracing pathways among the climate system, natural resources, human security, and social stability. Similarly, the climate security vulnerability hot spot study conducted by Busby et al. (2014a, b) points to locations where a large number of people could possibly die under climate conflict events by highlighting a repertoire of explanatory variables. For Brown and McLeman (2009, p. 294), "the identification of security risks and the prevention of conflict due to the impacts of climate change can be considered strongly linked to the identification of regions or populations that are vulnerable to climate change because of inadequate adaptive capacity". These studies advance variables that matter and explain why the security consequences of climate change are a "big" issue in some locations and less at other places. Further, Papaioannou's (2016) disaggregated, sub-national study presents a detailed scoping assessment of contextual conditions that provide a robust qualitative and quantitative evidence for climate shocks in conflict mechanisms. Several other studies also show the distinctive manner in which contextual vulnerability assessment can offer explanatory power to support distinct causal pathways and dynamics (Fjelde and von Uexkull, 2012; Zografos et al., 2014).

Given that contextual vulnerability represents dominant portrayal of vulnerability in climate conflict studies, and offers a promising entry point for analysts, researchers, and policy-makers aiming for a robust disentangling of the climate conflict nexus, we find reasons to advocate a framing of climate conflict as a vulnerability-based question that orients towards a needs-based agenda advanced in Raleigh et al. (2014). Such an agenda seeks to rescale the debate "bottom-upward" to highlight specificity and differences, and to combine threat-centred thinking and rhetoric about dangers emanating from climate shocks with a discourse along simplistic contextual vulnerability lines (Jasparro and Taylor, 2008). Specifically, it asks what makes people vulnerable; questioning the trajectories of conditional forces at the root of social tensions (such as spatialities of economic and geopolitical powers driving, for example, strategic resource manoeuvring over e.g. land), which for Adger et al. (2013) is one overlooked dimension. Casting climate conflict as a vulnerability-based question, therefore, supports 
making vulnerability and adaptability the central analytical issues (Adger, 2010). It orients the research towards fundamentally rebalancing the missing synergy between the climate science and social science communities (see Lewis and Lenton, 2015) and suggests taking into account the deterministic storyline regarding causes of peace and cooperation under climate change (Gemenne et al., 2014). Indeed, the considerable range of knowledge this can generate has been voiced (Slow, 2013; King and Mutter, 2014), especially in the hope for more convergence and consensual results (Ide and Scheffran, 2014).

Overall, contextual vulnerability can support a constructivist theory-informed climate conflict scholarship in three ways: (i) unravelling contextual totalities (e.g. a turn towards contextualised political ecologies of climate vulnerabilityconflict pathways in which concrete socio-political phenomena are analysed, including how "enclosure, territorialisation, and market strategies of accumulation by dispossession" may drive conflicts associated with land acquisition practices under climate change (Dunlap and Fairhead, 2014, p. 19), (ii) highlighting historicity, specificity, and variability (difference) of social structures and processes that seek to resolve complexity rather than pursuing predictability; and (iii) demonstrating flexibility in ways that incorporate contextual knowledge across space and time, and that challenges existing order (Selby, 2014). Further, a contextual vulnerability frame can enrich policies that are more socially focused and that include options on resource diversification, poverty reduction, conservation of common property resources, strengthening of collective adaptation actions, and so on. These point to resilience-building as an essential transformative process for areas affected by climate conflict.

Reviewers noted a growing discursive shifts towards resilience as a key nodal point in the climate conflict debate. Although this paper is not concerned about which of resilience and vulnerability is dominant in climate conflict debates, we observe that a shift towards resilience cannot completely ignore discussions about vulnerability (Vivekananda et al., 2014). Resilience and vulnerability are inextricably linked - since to reduce vulnerability to climate conflict is to strengthen resilience (Busby et al., 2014a). Indeed, vulnerability seems to have emerged alongside resilience in climate conflict debates (Von Lucke et al., 2014). Considering differences in research interests, we note that vulnerability seems to have relevance when the focus is about understanding climate conflict transmission mechanisms or facilitating factors (see Fjelde and von Uexkull, 2012; Von Uexkull, 2014). Resilience, in contrast, is stressed when the interest is about unpacking and executing climate conflict (adaptive) solutions during and/or after a violent event (Vivekananda et al., 2014). Similarly, studies emphasising "migration" within the context centrism frame tend to invoke a discursive shift towards resilience (e.g. Methmann and Oels, 2015). While we recognise the growing interest in resilience thinking within the climate conflict debate, our analysis suggests that it is the con- text centrism discourse frame that may best demonstrate the resilience storyline.

Further, although our focus is mainly on contextual vulnerability, our argument does not suggest that the outcome interpretation of vulnerability will be irrelevant for climate conflict studies. Given the projected changes in climate for several regions it is possible that most of what we know about vulnerability "conditional factors" and processes in climate conflict research will be insufficient to support our explanatory power of future climate-conflict links (Lewis, 2013; Lewis and Lenton, 2015). This is where outcome vulnerability might be useful. However, its limitation remains its inability to capture gross climate impacts and social adaptations (Füssel, 2007). Since climate conflict reflects a continuum of conditional forces, a deeper diagnosis of current climate conflict vulnerabilities can enable vulnerabilities to future climate conflict conditions to be addressed.

\section{Conclusions}

Discourses of climate conflict serve to articulate the variety of associations between climate change and conflict. The analysis presented here illustrates that there are multiple ways of conceiving how discourses are constructed, with different considerations for how climate conflict phenomena should be understood, including assumptions about causality, normative judgements, and vulnerability portrayals. While there is an absence of a specific interpretation of vulnerability in much of the discourses, we outline an orientation towards contextual vulnerability in both context centrism and denial claims discourses. This orientation is consistent with the portrayal of climate conflict as a continuum of socially determined factors that coalesce around extremely vulnerable systems. More importantly, as the somewhat "indirect link" premise regarding climate conflict relations has found its way into popular consciousness, we find most problematic the challenge associated with the point of entry for interpretation of climate conflict links. Current insights illustrate that a deterministic narrative of scarcity-induced conflict and a "threat-centred" type of thinking can downplay the prospect of pinning down more subtle interactions between climate change and conflict. In this light, an inclination towards contextual vulnerability offers a useful direction on how we might understand conflict in more complex ways rather than through climate change. This idea invokes the notion of contextual totalities, and embodies the complexity of the climate conflict challenge in the frame of historicity, specificity and variability. Similarly, the idea points to what may constitute parts of an integrative framework's requirements for modelling pathways between climate change, land use, and conflict (see Link et al., 2015).

Although the various discourses presented here have had a lot of purchase in the public domain where security experts and climate change practitioners speak different languages 
and consult different assessment tools, this paper suggests that climate conflict discourses can be better portrayed as a flow of socially constructed knowledge using a language that communicates vulnerability and powerlessness. In this way climate conflict can be presented as an issue that cuts across several disciplines, the type that embraces theories across notions of access, control, and struggle in which the precise and changing interactions of power, governance, institutions, and investments are a part. Indeed, there is a need to integrate existing knowledge within a contextual vulnerability perspective. It is our contention that since much of climate conflict articles in the frame of context centrism reveals a compelling priority for human security in Africa, casting the climate conflict storyline as a vulnerability-based question would re-enforce a needs-based agenda that allows for more convergence and consensual argument for any area affected by climate conflict.

Acknowledgements. The authors would like to thank Michael Brzoska, Matt McDonald and two anonymous reviewers for valuable comments on previous versions of this article.

Edited by: M. Brzoska

\section{References}

Adger, W. N.: Climate change, human well-being and insecurity, New Polit. Econ., 15, 275-292, 2010.

Adger, W. N., Benjaminsen, T., Brown, K., and Svarstad, H.: Advancing a political ecology of global environmental discourses, Dev. Change, 32, 681-715, 2001.

Adger, W. N., Barnett, J., and Debelko, G.: Climate and war: a call for more research, Nat. Clim. Change, 498, 171, 2013.

Anderson, C. and DeLisi, M.: Implications of global climate change for violence in developed and developing countries, in: The Psychology of Social Conflict and Aggression, edited by: Forgas, J., Kruglanski, A., and Williams, K., Psychology Press, New York, 249-265, 2011.

Atkinson, K., Koenka, A., Sanchez, C., Moshontz, H., and Cooper, H.: Reporting standards for literature searches and report inclusion criteria: making research syntheses more transparent and easy to replicate, Res. Synth. Meth., 6, 87-95, 2015.

Barnett, J. and Adger, W.: Climate change, human security and violent conflict, Polit. Geogr., 26, 639-655, 2007.

Bergholt, D. and Lujala, P.: Climate-related natural disasters, economic growth and armed civil conflict, J. Peace Res., 49, 147$162,2012$.

Brown, O. and McLeman, R.: A recurring anarchy? The emergence of climate change as a threat to international peace and security, Conflict Secur. Dev., 9, 289-305, 2009.

Buhaug, H.: Climate not to blame for African civil wars, P. Natl. Acad. Sci. USA, 107, 16477-16482, 2010.

Buhaug, H.: Climate-conflict research: some reflections on the way forward, WIREs Clim. Change, 6, 269-275, 2015.

Buhaug, H., Gleditsch, N. P., and Theisen, O. M.: Implications of Climate Change for Armed Conflict, Presented to the World
Bank Workshop on Social Dimensions of Climate Change, 56 March 2008, The World Bank, Washington, D.C., 1-48, 2008.

Buhaug, H., Nordkvelle, J., Bernauer, T., Böhmelt, T., Brzoska, M., Busby, J. W., Ciccone, A., Fjelde, H., Gartzke, E., Gleditsch, N. P., Goldstone, J., Hegre, H., Holtermann, H., Koubi, V., Link, J. S., Link, P. M., Lujala, P., O'Loughlin, J., Raleigh, C., Scheffran, J., Schilling, J., Smith, T. G., Theisen, O. M., Tol, R. S. J., Urdal, H., and von Uexkull, N.: One effect to rule them all? A comment on climate and conflict, Climatic Change, 127, 391-397, 2014.

Burke, M., Miguel, E., Satyanath, S., Dykema, J., and Lobell, D.: Warming increases the risk of civil war in Africa, P. Natl. Acad. Sci. USA, 106, 20670-20674, 2009.

Busby, J. W.: Who cares about the weather? Climate change and U.S. National Security, Secur. Stud., 17, 468-504, 2008.

Busby, J. W., Cook, K., Vizy, E., Smith, T., and Bekalo, M.: Identifying hot spots of security vulnerability associated with climate change in Africa, Climatic Change, 124, 717-731, 2014a.

Busby, J. W., Smith, T., and Krishnan, N.: Climate security vulnerability in Africa mapping 3.0, Polit. Geogr., 43, 51-67, $2014 \mathrm{~b}$.

Detraz, N.: Threats or vulnerabilities? Assessing the link between climate change and security, Global Environ. Polit., 11, 104-120, 2011.

Deudney, D.: The case against linking environmental degradation and national security, Millennium-J. Int. St., 19, 461-476, 1990.

Devlin, C. and Hendrix, C. S.: Trends and triggers redux: climate change, rainfall, and interstate conflict, Polit. Geogr., 43, 27-39, 2014.

Doulton, H. and Brown, K.: Ten years to prevent catastrophe? Discourses of climate change and international development in the UK press, Global Environ. Change, 19, 191-202, 2009.

Dryzek, J.: The Politics of the Earth: Environmental Discourses, 2nd Edn., Oxford University Press, Oxford, 2005.

Dumaine, C. and Mintzer, I.: Confronting climate change and reframing security, SAIS Review of International Affairs, 35, 5-16, 2015.

Dunlap, A. and Fairhead, J.: The militarisation and marketisation of nature: an alternative lens to "climate-conflict", Geopolitics, 19, 937-961, 2014.

Fjelde, H. and von Uexkull, N.: Climate triggers: rainfall anomalies, vulnerability and communal conflict in sub-Saharan Africa, Polit. Geogr., 31, 444-453, 2012.

Floyd, R.: The environmental security debate and its significance for climate change, Int. Spect.: Ital. J. Int. Affairs, 43, 51-65, 2008.

Floyd, R.: Global climate security governance: a case of institutional and ideational fragmentation, Conflict Secur. Dev., 15, 119-146, 2015.

Foucault, M.: Discipline and Punish: the Birth of the Prison, Pantheon Books, New York, 1979.

Foucault, M.: Politics and the study of discourse, in: The Foucault Effect: Studies in Governmentality, edited by: Burchell, G., Gordon, C., and Miller, P., Harvest Wheat-sheaf, London, 53-73, 1991.

Füssel, H. M.: Vulnerability: a generally applicable conceptual framework for climate change research, Global Environ. Change, 17, 155-167, 2007.

Füssel, H. M. and Klein, R.: Climate change vulnerability assessments: an evolution of conceptual thinking, Climatic Change, 75, 301-329, 2006. 
Gartzke, E.: Could climate change precipitate peace?, J. Peace Res., 49, 177-192, 2012.

Gemenne, F., Barnett, J., Adger, W., and Dabelko, G.: Climate and security: evidence, emerging risks, and a new agenda, Climatic Change, 123, 1-9, 2014.

Gleditsch, N. P.: Whither the weather? Climate change and conflict, J. Peace Res., 49, 3-9, 2012.

Hajer, M.: The Politics of Environmental Discourse: Ecological Modernisation and the Policy Process, Oxford University Press, Oxford, 1995.

Hartmann, B.: Rethinking climate refugees and climate conflict: rhetoric, reality and the politics of political discourse, Int. Dev., 22, 233-246, 2010.

Hendrix, C. and Salehyan, I.: Climate change, rainfall, and social conflict in Africa, J. Peace Res., 49, 35-50, 2012.

Hewitt, S.: Discourse analysis and public policy research, Newcastle University Centre for Rural Economy Discussion Paper Series No. 24, Newcastle University Centre for Rural Economy, Newcastle, 1-16, 2009.

Hopkins, D.: Applying a comprehensive contextual climate change vulnerability framework to New Zealand's tourism industry, Ambio, 44, 110-120, 2014.

Hsiang, S., Meng, K., and Cane, M.: Civil conflicts are associated with the global climate, Nature, 476, 438-441, doi:10.1038/nature10311, 2011.

Hsiang, S., Burke, M., and Miguel, E.: Quantifying the influence of climate on human conflict, Science, 341, 1235367, doi:10.1126/science.1235367, 2013.

Ide, T.: Why do conflicts over scarce renewable resources turn violent? A qualitative comparative analysis, Global Environ. Change, 33, 61-70, doi:10.1016/j.gloenvcha.2015.04.008, 2015.

Ide, T. and Fröhlich, C.: Socio-environmental cooperation and conflict? A discursive understanding and its application to the case of Israel and Palestine, Earth Syst. Dynam., 6, 659-671, doi:10.5194/esd-6-659-2015, 2015.

Ide, T. and Scheffran, J.: On climate, conflict and cumulation: suggestions for integrative cumulation of knowledge in the research on climate change and violent conflict, Global Change Peace Secur., 26, 263-279, doi:10.1080/14781158.2014.924917, 2014.

Ide, T., Schilling, J., Link, J., Scheffran, J., Ngaruiya, G., and Weinzierl, T.: On exposure, vulnerability and violence: spatial distribution of risk factors for climate change and violent conflict across Kenya and Uganda, Polit. Geogr., 43, 68-81, doi:10.1016/j.polgeo.2014.10.007, 2014.

IPCC: Climate Change 2007: Synthesis Report, in: Contribution of the Working Groups I, II and III to the Fourth Assessment Report of the Intergovernmental Panel on Climate Change, edited by: Pachauri, R. K. and Reisinger, A., IPCC, Geneva, Switzerland, 104 pp., 2007.

IPCC: Summary for policymakers, in: Climate Change 2014: Impacts, Adaptation, and Vulnerability, Part A: Global and Sectoral Aspects, Contribution of Working Group II to the Fifth Assessment Report of the Intergovernmental Panel on Climate Change, edited by: Field, C. B., Barros, V. R., Dokken, D. J., Mach, K. J., Mastrandrea, M. D., Bilir, T. E., Chatterjee, M., Ebi, K. L., Estrada, Y. O., Genova, R. C., Girma, B., Kissel, E. S., Levy, A. N., MacCracken, S., Mastrandrea, P. R., and White, L. L., Cambridge University Press, Cambridge, UK and New York, NY, USA, 1-32, 2014.
Jasparro, C. and Taylor, J.: Climate change and regional vulnerability to transnational security threats in Southeast Asia, Geopolitics, 13, 232-256, 2008.

Kallis, G. and Zografos, C.: Hydro-climatic change, conflict and security, Climatic Change, 123, 69-82, 2014.

Kelly, P. and Adger, W.: Theory and practice in assessing vulnerability, Climatic Change, 47, 325-352, 2000.

King, E. and Mutter, J.: Violent conflicts and natural disasters: the growing case for cross-disciplinary dialogue, Third World Q., 35, 1239-1255, 2014.

Koubi, V., Bernauer, T., Kalbhenn, A., and Spilker, G.: Climate variability, economic growth, and civil conflict, J. Peace Res., 49, 113-127, 2012.

Koubi, V., Spilker, G., Bohmelt, T., and Bernauer, T.: Do natural resources matter for interstate and intrastate armed conflict?, J. Peace Res., 51, 227-243, 2013.

Leach, M., Mearns, R., and Scoones, I.: Environmental entitlements: dynamics and institutions in community-based natural resource management, World Dev., 27, 225-247, 1999.

Lewis, K.: Climate science in climate security scenarios, Climatic Change, 123, 11-22, 2013.

Lewis, K. and Lenton, T.: Knowledge problems in climate change and security research, Wiley Interdisciplin. Rev.: Clim. Change, 6, 383-399, doi:10.1002/wcc.346, 2015.

Link, P. M, Brücher, T., Claussen, M., Link, J. S., and Scheffran, J.: The nexus of climate change, land use and conflict: complex human-environment interactions in northern Africa, B. Am. Meteorol. Soc., 96, 1561-1564, doi:10.1175/BAMS-D-15-00037.1, 2015.

Ludwig, R., Roson, R., Zografos, C., and Kallis, G.: Towards an inter-disciplinary research agenda on climate change, water and security in southern Europe and neighboring countries, Environ. Sci. Policy, 14, 794-803, 2011.

Mason, M. and Zeitoun, M.: Questioning environmental security, Geogr. J., 179, 294-297, 2013.

Mason, M., Zeitoun, M., and El Sheikh, R.: Conflict and social vulnerability to climate change: lessons from Gaza, Clim. Dev., 3, 285-297, 2011.

McDonald, M.: Discourses of climate security, Polit. Geogr., 33, 42-51, 2013.

Meierding, E.: Climate change and conflict: avoiding small talk about the weather, Int. Stud. Rev., 15, 185-203, 2013.

Methmann, C. and Oels, A.: From 'fearing' to 'empowering' climate refugees: Governing climate-induced migration in the name of resilience, Secur. Dialogue, 46, 51-68, 2015.

Morales Jr., E.: Global climate change as a threat to US National Security, J. Strat. Secur., 8, 134-148, 2015.

Müller, M.: Reconsidering the concept of discourse for the field of critical geopolitics: towards discourse as language and practice, Polit. Geogr., 27, 322-338, 2008.

O'Brien, K., Eriksen, S., Schjolden, A., and Nygaard, L.: What's in a word? Conflicting interpretations of vulnerability in climate change research, CICERO Working Paper 04, Center for International Climate and Environmental Research (CICERO), Oslo, Norway, 1-16, 2004.

O'Brien, K., Eriksen, S., Nygaard, L. P., and Schjolden, A.: Why different interpretations of vulnerability matter in climate change discourses, Clim. Policy, 7, 73-88, 2007. 
O’Loughlin, J., Witmer, F., Linke, A., Laing, A., Gettelman, A., and Dudhia, J.: Climate variability and conflict risk in East Africa, 1990-2009, P. Natl. Acad. Sci., 109, 18344-18349, 2012.

O'Loughlin, J., Linke, A., and Witmer, F.: Modeling and data choices sway conclusions about climate-conflict links, P. Natl. Acad. Sci. USA, 111, 2054-2055, 2014.

O'Neil, A.: Conceptualising future threats to Australia's security, Aust. J. Polit. Sci., 46, 19-34, 2011.

Papaioannou, K. J.: Climate shocks and conflict: evidence from colonial Nigeria, Polit. Geogr., 50, 33-47, 2016.

Rafey, W. and Sovacool, B.: Competing discourses of energy development: the implications of the Medupi coal-fired power plant in South Africa, Global Environ. Change, 21, 1141-1151, doi:10.1016/j.gloenvcha.2011.05.005, 2011.

Raleigh, C. and Kniveton, D.: Come rain or shine: an analysis of conflict and climate variability in East Africa, J. Peace Res., 49, 51-64, 2012.

Raleigh, C., Linke, A., and O'Loughlin, J.: Extreme temperatures and violence, Nat. Clim. Change, 4, 76-77, 2014.

Raleigh, C., Jin, H., and Kniveton, D.: The devil is in the details: an investigation of the relationships between conflict, food price and climate across Africa, Global Environ. Change, 32, 187-199, 2015.

Schafer, M., Scheffran, J., and Penniket, L.: Securitization of media reporting on climate change? A cross-national analysis in nine countries, Secur. Dialogue, 47, 76-96, doi:10.1177/0967010615600915, 2016.

Scheffran, J., Brzoska, M., Kominek, J., Link, P. M., and Schilling, J.: Climate change and violent conflict, Science, 336, 869-871, 2012a.
Scheffran, J., Brzoska, M., Kominek, J., Link, P., and Schilling, J.: Disentangling the climate-conflict nexus: empirical and theoretical assessment of vulnerabilities and pathways, Rev. Eur. Stud., 4, 1-13, 2012b.

Selby, J.: Positivist climate conflict research: a critique, Geopolitics, 19, 829-856, 2014.

Selby, J. and Hoffmann, C.: Beyond scarcity: rethinking water, climate change and conflict in the Sudans, Global Environ. Change, 29, 360-370, 2014.

Sherbinin, A.: Climate change hotspots mapping: what have we learned?, Climatic Change, 123, 23-37, 2014.

Slow, A. R.: A call for peace on climate and conflict, Nature, 497, 179-180, 2013.

Theisen, O. M., Holtermann, H., and Buhaug, H.: Climate wars? Assessing the claim that drought breeds conflict, Int. Secur., 36, 79-106, 2012.

Vivekananda, J., Schilling, J., and Smith, D.: Understanding resilience in climate change and conflict affected regions of Nepal, Geopolitics, 19, 911-936, 2014.

Von Lucke, F., Wellmann, Z., and Diez, T.: What's at stake in securitising climate change? Towards a differentiated approach, Geopolitics, 19, 857-884, 2014.

Von Uexkull, N.: Sustained drought, vulnerability and civil conflict in sub-Saharan Africa, Polit. Geogr., 43, 16-26, doi:10.1016/j.polgeo.2014.10.003, 2014.

Wischnath, G. and Buhaug, H.: On climate variability and civil war in Asia, Climatic Change, 122, 709-721, 2014.

Zografos, C., Goulden, M., and Kallis, G.: Sources of human insecurity in the face of hydro-climatic change, Global Environ. Change, 29, 327-336, 2014. 